\title{
CONCEPÇÕES DE SAÚDE ENTRE DOCENTES DE BIOLOGIA: UM INSTRUMENTO INVESTIGATIVO
}

\author{
Conceptions of health among biology teachers: an investigative tool
}

WeltonYudi Oda ${ }^{11}$

\begin{abstract}
RESUMO
Apresenta-se aqui um instrumento investigativo para uso em pesquisas que visem compreender as concepções de saúde de professores de biologia da educação básica e/ou do ensino superior. Elemento central na construção do instrumento é a compreensão da relevância da dimensão sociohistórica na gênese e nos processos de transformação do saber, como indica o modelo explicativo fleckiano da sociogênese do conhecimento. Contribuição relevante à elaboração do questionário é oferecida por Barata (1985), que constrói um esquema que sistematiza concepções de saúde ao longo da história humana. O presente instrumento foi submetido à validação e, em seguida, utilizado para indicar as concepções de docentes universitários de Parasitologia e Microbiologia em estudo mais amplo, em que se investigou a sua constituição docente. Os resultados desta primeira utilização em processos investigativos do questionário detectaram a presença de três distintos perfis docentes quanto às concepções de saúde: os indefinidos, os que rejeitam a causação social e aqueles que rejeitam as concepções mais simplistas de saúde, como o higienismo e o biologicismo. Por seu caráter quantitativo, o instrumento é recomendado para fases iniciais da pesquisa, auxiliando, por exemplo, na fase preliminar da investigação, na triagem e seleção da amostra para pesquisas mais pormenorizadas, de caráter predominantemente qualitativo.
\end{abstract}

Palavras-chave - instrumento de pesquisa, concepções de saúde, professores de biologia, causação social, biologicismo.

\section{ABSTRACT}

It is presented here an investigative tool for use in research aimed at understanding the health concepts of biology teachers in basic education and/or higher education. Central element in the construction of the investigative tool is the understanding of the relevance of the sociohistorical dimension in the genesis and in the transformation processes of knowledge, as indicated by the explanatory fleckian model of knowledge sociogenesis. Important contribution to the development of the questionnaire is offered by Barata (1985), which constructs a scheme that systematizes health concepts throughout human history. This tool was validated and then used to indicate the views of Parasitology and Microbiology university professors in a broader study, in which was investigated its academic genesis. The results of this first use in investigative processes of the questionnaire detected the presence of three distinct teachers' profiles regarding the concepts of health: The undefined, those who reject

\footnotetext{
${ }^{1}$ Doutor em Educação Científica e Tecnológica pela Universidade Federal de Santa Catarina
} 
the social causation and those who reject the simplistic conceptions of health, as hygienism and biologicism. Due to its quantitative character, the investigative tool is recommended for early stages of research, helping, for example, during the preliminary investigation, in the screening and selection of the sample for a more detailed research, of predominantly qualitative character.

Keywords - investigative tool, health conceptions, biology teachers, social causation, biologicism.

\section{PORQUE ESTUDAR CONCEPÇÕES DE SAÚDE ENTRE DOCENTES?}

Presentemente, no início do século XXI, o chamado "Paradigma da Microbiologia" - instituído a partir do desenvolvimento de instrumentos óticos que possibilitaram a visualização e o estudo de microrganismos, como bactérias, protozoários e fungos, sobretudo nos séculos XVIII e XIX - parece estar vivenciando sua crise, caso adotemos o modelo de sociogênese do conhecimento científico proposto por Thomas Kuhn (2007). Nessa fase, segundo o modelo explicativo desenvolvido por outro epistemólogo, o polonês Ludwik Fleck (2010), acentuam-se as complicações, as situações para as quais determinado Estilo de Pensamento ${ }^{2}$ (EP) perde sua capacidade heurística.

No estudo sobre a sociogênese de conhecimentos e práticas desenvolvido por Fleck (2010), ao analisar sua produção e disseminação no interior daquilo que denominou de Coletivos de Pensamento, o pensador, assim como Kuhn (2007), indica a relevância de suas dimensões histórica e social, para a compreensão da dinâmica das transformações no conhecimento.

Por este motivo, muitos estudos envolvendo concepções e práticas docentes recorrem a estratégias que possibilitem compreender a gênese e as transformações históricas ocorridas nas concepções de ciência e de saúde, por exemplo, como os desenvolvidos por Delizoicov (1995) e Cutolo e Delizoicov (2003). O primeiro deles investiga as concepções de saúde de professores de biologia, detectando a presença de distintas visões entre os participantes de sua pesquisa, além de identificar a gênese histórica de tais concepções. $\mathrm{O}$ segundo, por sua vez, pesquisa as práticas curriculares na educação médica, investigando concepções de saúde e doença. Nesse segundo estudo, indicam que a problemática subjacente às limitadas compreensões observadas diz respeito, sobretudo, a questões de natureza epistemológica relacionadas ao modelo hegemônico neste campo educacional.

Importante ressaltar que, dado que as concepções de saúde dos docentes interferem diretamente no modo como efetivam sua prática docente, compreender como estes profissionais concebem a saúde será útil, na medida em que isto terá impacto direto na formação do cidadão, mas também (no caso do docente do ensino superior) na de farmacêuticos, médicos, odontólogos, enfermeiros e biólogos, etc. Por este motivo, digno de

\footnotetext{
${ }^{2} O$ estilo de pensamento, assim como qualquer estilo, consiste numa determinada atmosfera e sua realização. Uma atmosfera possui dois lados inseparáveis: ela é a disposição para um sentir seletivo e para um agir direcionado correspondente. (...) Podemos definir, portanto, o estilo de pensamento como percepção direcionada em conjunção com o processamento correspondente no plano mental e objetivo (FLECK, 2010, p.149).
} 
nota também é o fato de que foi em estudo sobre a docência universitária em biologia em metrópoles amazônicas (ODA, 2012), no qual, dada a necessidade de conhecermos as concepções de saúde de professores de Parasitologia e Microbiologia, que se idealizou o instrumento que aqui será descrito. Sua idealização deu-se, portanto, num contexto de grande incidência de doenças parasitárias, como a malária, a leishmaniose, as verminoses intestinais, a hanseníase e a febre amarela (BRASIL, 2000; BRASIL, 2007).

\section{ELEMENTOS PRELIMINARES}

No estudo referido acima, uma tese de doutorado, buscou-se compreender a constituição, formação e atuação dos professores universitários, em particular daqueles que ministram disciplinas relacionadas à Parasitologia e Microbiologia. Nesse sentido, alinhado com a compreensão fleckiana relativa à dimensão sócio histórica do conhecimento, a investigação buscou não somente conhecer as atuais concepções de saúde dos docentes, mas também sua gênese histórica e, sobretudo, seus reflexos na prática de ensino destas disciplinas. Deste modo, foi necessária a realização de um estudo sobre as visões de saúde presentes na contemporaneidade e de suas transformações ao longo do tempo.

Compreendia-se, inicialmente, que o pensamento vigente no final do século XIX e início do século XX era baseado na crença de que a descoberta do mundo microbiológico correspondia à elucidação dos agentes "causadores" das doenças infecciosas. Isto poderia ser ilustrado com a seguinte afirmação: Agora a medicina não precisaria mais perder tempo com problemas sociais (BEHRING, 1893 apud FLECK, 2010).

$\mathrm{O}$ aprofundamento desta pesquisa histórica evidenciou que este EP, que conduziu à adoção de procedimentos médicos baseados, predominantemente, na identificação de "agentes etiológicos" e na consequente quimioterapia de infecções bacterianas, protozoóticas e helmínticas começa a ser alvo de frequentes críticas no final do século XX (ODA, 2012).

Barata (1985), criticando esta visão “microbiológica”, afirma que, segundo este pensar:

\footnotetext{
"a bacteriologia veio liberar a medicina dos complexos determinantes econômicos, sociais e políticos que a impediam de desenvolver-se cientificamente (Barata, 1985, p. 5)".
}

Já Da Ros (2000) assegura que um dos problemas, quando da origem deste estilo de pensamento, foi o fato de que a Microbiologia, ao invés de tornar-se importante instrumento para apoiar as explicações dadas pela Medicina Social, passa a significar uma ruptura com todo o conhecimento anterior. Este, embora baseado no conceito de miasmas ${ }^{3}$, levava em consideração a importância do meio ambiente na produção de endemias.

Um estudo mais pormenorizado e sistemático destas mudanças históricas, desenvolvido por Barata (1985), constituiu, entretanto, a base para a construção do presente instrumento.

\footnotetext{
${ }^{3}$ Conceito grego, descrito por Hipócrates, em seu Ares, águas e lugares, que correspondia à ideia de partículas que emanavam de lugares como pântanos e lagos e que, em contato com o homem, produziam doenças.
} 


\section{O MODELO EXPLICATIVO DE BARATA (1985)}

Para este autor, que investigou as mudanças históricas nas concepções de saúde, estas podem ser classificadas entre as unicausais e as multicausais.

Seu modelo registra, como ponto de partida, uma das mais antigas concepções unicausais, a qual remonta à Antiguidade. Esta visão atribui, tanto a elementos naturais como sobrenaturais (externos), a causação das doenças, tendo o corpo humano como receptáculo estático (DELIZOICOV, 1995, p. 48), visão denominada biologicista.

Outra visão, esta multicausal, viria da medicina hindu e chinesa:

A doença surge do desequilíbrio dos humores presentes no organismo humano. As causas deste desequilíbrio são externas, relacionadas ao ambiente físico, como a influência dos astros, clima e animais associados à doença, como, por exemplo, insetos. A saúde consiste no restabelecimento do equilíbrio da energia interna, através de práticas terapêuticas, como por exemplo, a acupuntura (DELIZOICOV, 1995, p. 48).

Distinta da visão biologicista, na visão primitiva de multicausalidade, o homem passa a desempenhar papel ativo no processo saúde-doença. Tal visão, aprofundada por gregos como Hipócrates, valorizou o papel do meio ambiente nos processos saúde-doença. Apesar de sua coerência interna, a multicausalidade primitiva é criticada por Barata (1985), que afirma que, muito embora reconheça a participação de distintos agentes na produção de doenças, considera-os separadamente, desprezando as interações, buscando focar no agente principal envolvido, tornando-se mecanicista e reducionista e assemelhada à visão unicausal.

Segundo o autor, um modelo mais bem acabado de multicausalidade é apresentado pelo modelo ecológico, que apresenta os fatores causais inter-relacionados sob a forma de um sistema fechado com um feedback regulador. Apesar disso, neste sistema o homem é apresentado em sua condição animal, desprovido dos complexos determinantes sociais.

Ludwik Fleck, que além de epistemólogo foi também um reconhecido microbiologista, também constrói seu modelo explicativo a partir da visão multicausal. Para ele, as doenças são resultado de interações multifatoriais e multidimensionais, sendo que as doenças podem ser, portanto, observadas de diferentes pontos de vista clínico, bacteriológico, psicológico, social, etc. (DA ROS, 2000, p. 22). Este autor, por sua vez, criticando a ideia de globalidade com que cada uma destas áreas, acima mencionadas, explica a doença, de forma suficiente, global e definitiva, chama a esta visão de harmonia das ilusões.

Apesar disso, defende esta visão multicausal, afirmando que, embora a capacidade de reconhecer determinado fenômeno implique em perda de habilidade de percebê-lo da forma como se percebia antes, tal processo compreende uma característica humana. Considera ainda a impossibilidade de organizar uma classificação de doenças que leve em consideração bilhões de variações, a não ser como mecanismo formal, que deve ser usado criticamente (DA ROS, 2000, p. 23).

Outra concepção, que emergiu do contexto da Revolução Francesa, é a causação social das doenças A partir de então, passou-se a relacionar as condições de vida e de trabalho das populações com o aparecimento de doenças (BARATA, 1985, p. 52). No modelo baratiano aqui explicitado, esta concepção constitui-se como mais complexa e bem acabada. Segundo o autor, a partir disso: 
o desenvolvimento teórico das ciências sociais permitiu, no final do século XVIII, a elaboração de uma teoria social da Medicina e, como consequência, as causas das doenças não foram mais buscadas no ambiente natural, mas no social, nas condições de vida e de trabalho do homem (BARATA, 1985, p. 52).

Importante ressaltar que, embora dispostas em ordem cronológica de surgimento, tais visões não se sucederam, linearmente, no tempo. $\mathrm{O}$ aperfeiçoamento dos instrumentos óticos, por exemplo, que originou o Paradigma da Microbiologia, fez com que boa parte dos microbiologistas, micologistas e parasitologistas dos séculos XX e XXI adotasse uma visão biologicista, atribuindo a um elemento externo, o germe, o aparecimento das doenças.

\section{A CONSTRUÇÃO DO INSTRUMENTO INVESTIGATIVO}

Ainda que outro modelo explicativo, no caso o proposto por Da Ros (2000), constitua um esquema mais complexo, contemplando onze distintos Estilos de Pensamento (EPs), adotamos o esquema elaborado por Barata (1985). Tal escolha fez-se pela percepção de que, como o modelo desenvolvido pelo primeiro envolveu a participação estrita de profissionais da área de saúde em sua formulação, distanciava-se, portanto, da situação para a qual buscamos construir o referido instrumento, qual seja, a de investigar as concepções de saúde entre docentes de Biologia. Ressalte-se, entretanto, que Da Ros (2000), ao identificar estes EPs, por meio da análise de dissertações e teses, também identifica nestes trabalhos essas distintas concepções de saúde, argumentando que um dos elementos que compõem cada um dos EPs caracterizados é a concepção de saúde compartilhada pelo CP.

O contexto da produção deste instrumento envolveu a necessidade de investigar concepções de saúde entre docentes universitários de biologia, pesquisa empírica associada à Tese de Doutorado intitulada "A docência universitária em biologia e suas relações com a realidade das metrópoles amazônicas” (ODA, 2012).

Outra referência para a construção da presente proposta, ainda que envolva tema distinto, foi o instrumento desenvolvido por Borges (1996) para investigar concepções de ciência entre docentes. O referido instrumento ofereceu, para a proposta ora apresentada, apenas um insight inicial e subsídios para apoiar a esquematização estrutural da presente proposta.

O desenvolvimento e os processos de validação do instrumento ocorreram durante a terceira fase dessa tese, etapa esta intitulada "Pesquisa in loco" (ODA, 2012, p. 85) e a referida investigação, integrante do projeto institucional "Avaliação qualitativa e quantitativa do Ensino das Ciências na Universidade Federal do Amazonas (UFAM)", foi aprovada pelo Comitê de Ética e Pesquisa daquela instituição, conforme parecer anexo à tese (ODA, 2012, P. 397).

Apesar de sua aplicação ter ocorrido numa fase investigativa caracterizada por abordagem metodológica predominantemente qualitativa, o presente instrumento (ANEXO 1) é adequado à investigação de cunho quantitativo. O instrumento é composto por um conjunto de afirmações, extraídas e adaptadas de Barata (1985), representativas das distintas concepções de saúde (biologicista, higienista, rede de causalidade, causação social), para os quais o docente deve posicionar-se valorativamente. Deste modo, para cada sentença apresentada, o participante deve assinalar valores de 1 a 4 , sendo que " 1 " representa a 
discordância total, enquanto "4" indica a concordância plena. Por compor-se de questões fechadas, o presente instrumento pode auxiliar na obtenção de grande quantidade de dados, ainda que, para o aprofundamento da investigação sobre concepções de saúde, requeira metodologia complementar de caráter qualitativo.

Importante ressaltar que as adaptações feitas às afirmações de Barata visaram unicamente a inseri-las no contexto da pesquisa, que foi realizada com docentes de Parasitologia e Microbiologia. Deste modo, foram inseridos termos como "parasitos", "doenças parasitárias", "vetores" e "agente etiológico", por exemplo, sempre que necessário. Uma comparação entre o esquema de Barata (1985) e as adaptações feitas para o contexto da pesquisa é efetivada na Tabela 1.

Na constituição do instrumento, a primeira e a segunda sentenças (ANEXO 1) foram concebidas buscando representar a visão de causação social das doenças e, enquanto a primeira busca detalhar tal visão, a segunda exige que o docente se posicione perante uma concepção de política pública de saúde pautada nesta concepção.

A terceira afirmação descreve a concepção denominada por Barata (1985) de rede de causalidade, enquanto a quarta não somente descreve a visão biologicista, como também pede que o participante da pesquisa se posicione quanto a medidas baseadas nesta concepção. A quinta frase descreve a multicausalidade primitiva, enquanto a sexta refere-se à visão denominada higienista (ANEXO 1).

Tabela 1 - Comparação entre o esquema de Barata (1985) e abordagem utilizada no instrumento de pesquisa desenvolvido por Oda (2012).

\begin{tabular}{|c|c|c|}
\hline Concepções de Saúde & Barata (1985) & Oda (2012) \\
\hline \multicolumn{3}{|l|}{ Unicausais } \\
\hline Biologicista & $\begin{array}{l}\text { Neste modelo, o corpo é um } \\
\text { receptáculo passivo das } \\
\text { doenças. }\end{array}$ & $\begin{array}{l}\text { Produz um enunciado baseado } \\
\text { na Parasitologia, atribuindo aos } \\
\text { agentes etiológicos à } \\
\text { responsabilidade exclusiva pela } \\
\text { doença. }\end{array}$ \\
\hline Higienista & $\begin{array}{l}\text { Baseado na ideia de miasmas, } \\
\text { atribui a responsabilidade } \\
\text { exclusiva da doença a estas } \\
\text { partículas. }\end{array}$ & $\begin{array}{l}\text { Ressalta visões socialmente } \\
\text { preconceituosas associadas, } \\
\text { indiretamente, ao higienismo e, } \\
\text { em outro enunciado, destaca a } \\
\text { verticalidade das ações pautadas } \\
\text { no modelo. }\end{array}$ \\
\hline \multicolumn{3}{|l|}{ Multicausais } \\
\hline $\begin{array}{l}\text { Multicausalidade } \\
\text { primitiva }\end{array}$ & $\begin{array}{l}\text { Oriundo das medicinas hindu e } \\
\text { chinesa, baseia-se na ideia de } \\
\text { que saúde-doença associam-se } \\
\text { com o equilíbrio entre humores } \\
\text { corporais. }\end{array}$ & - \\
\hline $\begin{array}{l}\text { Modelo da Rede de } \\
\text { Causalidade }\end{array}$ & $\begin{array}{l}\text { A saúde é vista como } \\
\text { equilíbrio entre diversos } \\
\text { fatores que envolvem } \\
\text { hospedeiro, agente e meio- } \\
\text { ambiente. O autor considera-o }\end{array}$ & $\begin{array}{l}\text { Utiliza-se da caracterização de } \\
\text { Barata (1985), ressaltando que, } \\
\text { na prática, as ações centradas } \\
\text { neste modelo transformam-no } \\
\text { em unicausal. }\end{array}$ \\
\hline
\end{tabular}




\begin{tabular}{|c|l|l|}
\hline & mecanicista e reducionista. & \\
\hline Modelo Ecológico & $\begin{array}{l}\text { As inter-relações entre fatores } \\
\text { causais da saúde/doença são } \\
\text { apresentados sob a forma de } \\
\text { um sistema fechado com um } \\
\text { feed-back regulador. O homem } \\
\text { afeta e é afetado pelo meio. } \\
\text { Barata considera o modelo o } \\
\text { mais bem acabado, dentre os } \\
\text { multicausais. }\end{array}$ & \\
\hline Sociais & $\begin{array}{l}\text { Surgiu a partir da Revolução } \\
\text { Francesa e atribui a doença a } \\
\text { condições sociais degradantes. } \\
\text { As relações socioculturais } \\
\text { entre os homens são tratadas } \\
\text { de modo distinto neste modelo. }\end{array}$ & $\begin{array}{l}\text { Utiliza o exemplo da tuberculose } \\
\text { no século XIX para ilustrar o } \\
\text { modelo. }\end{array}$ \\
\hline & \multicolumn{2}{|l}{} \\
\hline
\end{tabular}

Para a validação do presente instrumento, solicitamos a dois docentes universitários, integrantes do quadro de professores de uma instituição pública de ensino de Santa Catarina, sendo um de Parasitologia e outro de Microbiologia, que respondessem ao questionário. Os participantes assinaram, previamente, o Termo de Consentimento Livre e Esclarecido (TCLE), sendo informados sobre o teor da pesquisa e sobre a garantia de que a identidade dos informantes seria mantida em sigilo. Além disso, sugerimos a eles que apontassem possíveis dificuldades de compreensão ou eventuais falhas que pudessem gerar interpretação dúbia, além de inserirem, caso necessário, comentários, adendos e críticas. Poucas sugestões ou críticas foram feitas pelos docentes, as quais foram incorporadas ao modelo inicial, mas, de modo geral, o instrumento foi considerado compreensível e relativamente simples.

\section{ABORDAGEM QUANTITATIVA NA PESQUISA EM EDUCAÇÃO?}

Cabe ressaltar, para iniciarmos a exposição deste tópico, que a posição assumida, durante a investigação que originou o instrumento investigativo aqui apresentado (ODA, 2012) considera falsa a contraposição entre as abordagens quantitativa e qualitativa.

Isso posto, registre-se que a tradição de pesquisas em educação é predominantemente qualitativa, ainda que Lima (2001) registre que a presença e a influência do paradigma quantitativo na área educacional foi e ainda o é considerável, mesmo no momento histórico atual (p. 38).

Gatti (2004), apontando a escassez do uso da abordagem quantitativa em pesquisas educacionais, indica certo preconceito e razões ideológicas reificadas a priori. Sobre essa abordagem, Lima (2001) afirma que a sua utilidade é necessária, no entanto, situando-a num contexto de colaboração com o labor científico e nunca como o "paradigma da verdade absoluta" (p. 39). Alves (1991) acrescenta ainda que

criou-se, pelo menos entre aqueles que se guiam pela vulgata qualitativa, uma espécie de ojeriza ao número, como se fosse desprovido de significado 
ou tivesse o poder de macular a pureza paradigmática (ALVES, 1991, p. 16).

A referida autora, neste mesmo estudo, atribui o uso de expressões "vagas" como muitos ou a maioria, em muitas pesquisas qualitativas à falta de uma tradição mais sólida em lidar com a abordagem quantitativa. Deste modo, constata-se que estes pesquisadores, que se debruçaram sobre o estudo da metodologia investigativa no campo educacional, são unânimes em apontar: a) a predominância, e quase exclusividade, da abordagem qualitativa nas pesquisas em educação; b) a falta de tradição e a necessidade de uso mais frequente da abordagem quantitativa e, por fim; c) a necessidade de integração entre as duas abordagens.

Algumas das razões apontadas pela literatura para a utilização de análises quantitativas incluem a contextualização e compreensão de certos problemas educacionais, como dados demográficos e medidas, por exemplo (GATTI, 2004). Adicionalmente, Alves (1991) afirma não ter dúvidas quanto à validade da utilização de técnicas quantitativas e qualitativas numa mesma pesquisa. Serapioni (2000) aponta para a pouca frequencia de trabalhos que buscam a integração entre estas abordagens, já que a maioria deles foca na sua contraposição.

Esta integração não significa a mera instrumentalização dos dados quantitativos na abordagem qualitativa, já que a abordagem quantitativa possui seu instrumental analítico próprio. Além disso, a mera adoção acrítica de números e proporções, por pesquisas qualitativas, manteria a crença ingênua de certos pesquisadores em quaisquer bases de dados, denunciada por Gatti (2004). Deste modo, uma verdadeira integração exigirá do pesquisador do campo educacional, ainda inexperiente nesta abordagem, um contato com especialistas no uso de testes estatísticos, técnicas de amostragem, delineamento experimental, entre outros conhecimentos especializados da tradição da pesquisa quantitativa.

\section{RESULTADOS PRELIMINARES}

Como é próprio deste tipo de abordagem, a pesquisa pode servir para a obtenção de dados de caráter mais abrangente e com menor nível de detalhamento. Assim, um instrumento desta natureza poderia ser aplicado a centenas ou até milhares de docentes, visando a delinear um quadro geral pouco detalhado. Esta estratégia serve, por exemplo, para a seleção da amostra para pesquisas mais detalhadas.

O instrumento foi aplicado, durante a já referida Pesquisa in loco da tese (ODA, 2012), a oito docentes de Parasitologia e Microbiologia de instituições públicas de Manaus e Belém, que também assinaram o TCLE. Os resultados foram apresentados e discutidos na referida tese (p. 128), entretanto, será apresentado, a seguir, um pequeno resumo destes achados. Ressalte-se que, como afirmado anteriormente, apesar do questionário ter sido aplicado a um número pequeno de docentes, situação ocorrida por certas contingências da pesquisa realizada, prestaria a atender a amostra bem maior do que esta.

Os participantes foram selecionados a partir de elementos considerados importantes em sua constituição docente, como o tempo de magistério superior, a formação inicial, a realização de Estágio Docente, o exercício da docência em outros níveis de ensino, etc. Dentre os selecionados, metade (4) apresentou concepções e práticas predominantemente tradicionais de ensino, enquanto a metade restante evidenciou, de modo oposto, um perfil docente diferenciado. 
Os resultados obtidos a partir da análise dos instrumentos respondidos pelos docentes evidenciaram que suas concepções de saúde são indefinidas. Por um lado, houve uma clara compreensão da importância de elementos sociais na causação das doenças e, por outro, uma adesão, por parte de muitos docentes, a visões mais simplistas, como o higienismo, o biologicismo e a multicausalidade primitiva, que desvalorizam a participação de tais elementos.

Raras foram as exceções, entretanto, um dos docentes posicionou-se de modo a discordar da participação de elementos sociais enquanto causadores de doenças. Nesse caso, sua concepção de saúde coadunou-se com sua concepção pedagógica, centrada na idéia de transmissão-recepção. Para o referido participante, portanto, bastaria, em sua atividade docente, ensinar medidas preventivas, por exemplo, para que o estudante "aprendesse".

Dois outros docentes apresentaram, em relação aos demais, uma pequena diferença, manifesta em menor adesão aos modelos explicativos mais simplistas, como o biologicismo e o higienismo. Tal diferença foi interpretada como devida à formação inicial dos docentes, ambos graduados em cursos da área de saúde.

Três distintos perfis, portanto, emergiram desta investigação preliminar: a) docentes cuja concepção é indefinida; b) docentes que desconsideram a causação social das doenças e; c) docentes com uma visão um pouco mais elaborada dos processos saúde-doença (em geral da área médica).

A percepção deste quadro parece indicar, para pesquisas futuras que busquem o aprofundamento do tema, que docentes com concepções mais representativas de cada um destes perfis devam compor a amostra de uma pesquisa com abordagem qualitativa, envolvendo entrevistas semiestruturadas, por exemplo, que pudessem indicar, de modo mais minucioso e acurado, um quadro descritivo das concepções de saúde e suas implicações nas atuais práticas educacionais dos docentes.

Os resultados acima descritos indicam ainda, preliminarmente, a adequação do referido instrumento no sentido de possibilitar sondagens sobre as concepções de saúde de docentes universitários de biologia. Além disso, ainda que não tenha sido objeto de investigação no presente estudo, pesquisas como a realizada por Delizoicov (1995) indicam que instrumentos desta natureza poderiam também ser aplicados entre docentes que atuam na educação básica.

\section{REFERÊNCIAS BIBLIOGRÁFICAS}

ALVES, A. J. O planejamento de pesquisas qualitativas em educação. Caderno de Pesquisas, São Paulo 77: 53-61. Maio 1991.

BARATA, R. B. A Historicidade do Conceito de Causa, in Textos de Apoio Epidemiologia 1. Rio de Janeiro. PEC/ENSP-ABRASCO, 1985.

BORGES, R. M. R. Em debate: Cientificidade e Educação em Ciências. Porto Alegre: Ed. CECIRS. 75p. 1996.

BRASIL. Ministério da Saúde. Doenças infecciosas e parasitárias: aspectos clínicos, de vigilância epidemiológica e de controle - guia de bolso / elaborado por Gerson Oliveira Pena [et al]. - Brasília : Ministério da Saúde : Fundação Nacional de Saúde, 2000. 
BRASIL. (2007) Epidemiologia e Serviços de Saúde. Secretaria de Vigilância em Saúde. - Brasília 16(4). Ministério da Saúde. ISSN 1679-4974. 225 p.

CUTOLO, L. R. A.; DELIZOICOV D. Caracterizando a escola médica brasileira. Arquivos Catarinenses de Medicina Florianópolis 2003: 32 (4): 24-34.

DA ROS, M. A. Estilos de Pensamento em Saúde Pública: um estudo da produção da FSP-USP e ENSP-FIOCRUZ, entre 1948 e 1994, a partir da epistemologia de Ludwik Fleck. 2000. 207p. Tese (Doutorado em Ensino de Ciências). Universidade Federal de Santa Catarina. Florianópolis. 2000.

DELIZOICOV, N. C. O Professor de Ciências Naturais e o Livro Didático. 1995. 128p. Dissertação (Mestrado em Educação). Universidade Federal de Santa Catarina. Florianópolis, 1995.

FLECK, L. Gênese e Desenvolvimento de um Fato Científico. Belo Horizonte: Fabrefactum. 2010.

GATTI, B. A. (2004) Estudos quantitativos em educação. Educação e Pesquisa, 30(1): 11-30.

LIMA, P. G. Tendências paradigmáticas na pesquisa educacional. 2001. 317p. Dissertação (Mestrado em Educação). Universidade Estadual de Campinas. Campinas, 2001.

SERAPIONI, M. (2000). Métodos qualitativos e quantitativos: algumas estratégias para a integração". Ciência \& Saúde Coletiva 5(1): 187-192.

KUHN, T. S. A Estrutura das Revoluções Científicas. 9a. Ed. Perspectiva. São Paulo. 2007. Pp. 9-17; 210-255.

ODA, W. Y. A docência universitária em biologia e suas relações com a realidade das metrópoles amazônicas. 2012. 358 p. Tese (Doutorado em Educação Científica e Tecnológica). Universidade Federal de Santa Catarina. Florianópolis, SC, 2012. 


\section{ANEXO 1 - Instrumento de Investigação}

Após a leitura das 13 questões abaixo, indique o seu grau de concordância com as mesmas, usando uma escala de 1 a 4 . Use 4 para indicar concordância plena, 3 para concordância parcial, 2 para discordância parcial e 1 para discordância total.

No século XIX a tuberculose tornou-se a doença social por excelência, porque a indústria arrancou os trabalhadores dos campos, obrigando-os a trabalhos ainda mais forçados, a viverem em moradias apinhadas, escuras, mal cheirosas e forçou as crianças a trabalhar até a noite. Em tais condições a tuberculose explodiu como fenômeno de massa.

Muitas medidas adotadas atualmente para lidar com doenças como a dengue, a malária e outras parasitoses são tomadas de cima pra baixo, sem o envolvimento da população acometida. Desse modo, resultam em constantes fracassos.

As doenças podem ser explicadas a partir do modelo de rede de causalidade, que considera as interações recíprocas entre os fatores na causação da doença. Com ele é possível, descobrindo o fator mais frágil, intervir neste e debelar a doença, ao invés de dispersar tempo e energia buscando atacar vários fatores.

São os parasitos que causam as doenças. Cada doença infecciosa e parasitária possui seu agente etiológico. É preciso compreender aspectos como a morfologia e a biologia dos parasitos, além das suas manifestações. O controle das populações destas espécies patogênicas e o tratamento dos doentes (com bactericidas, fungicidas, carrapaticidas, etc...) são as maneiras mais eficazes de combatermos as causas destas doenças.

A saúde é o equilíbrio entre fatores diversos e múltiplos que envolvem o hospedeiro, os vetores, o agente etiológico e o meio-ambiente. Por desequilíbrios centrados no hospedeiro ou no agente, ou por modificações do meio ambiente em direção ao hospedeiro ou ao agente, surge a doença.

A higiene individual é fundamental na prevenção das doenças parasitárias. Pessoas com menor poder aquisitivo possuem hábitos de higiene mais precários e por isso são mais susceptíveis a este tipo de doença. 